\title{
Coming Together: How Medical Students, Academic Administrators, and Hospital Administrators Approached Student Volunteering During the COVID-19 Pandemic
}

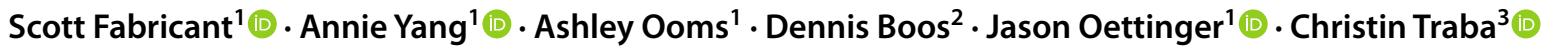

Accepted: 11 May 2021 / Published online: 19 May 2021

(C) International Association of Medical Science Educators 2021

\begin{abstract}
The COVID-19 pandemic caused dramatic interruptions and shifts to medical education, but students at schools nationwide responded by volunteering to support their physician educators on the frontlines. Relationships between student leaders, school administrators, and hospital administrators were key to the successful creation and organization of volunteer responses. This perspective piece from medical students, as well as hospital and medical school leadership, explores the evolving relationships in the creation of Rutgers New Jersey Medical School's Student COVID Team. By reflecting on choices made by each group in parallel points in time, the piece highlights where interests and actions aligned and diverged.
\end{abstract}

Keywords COVID-19 $\cdot$ Emergency response $\cdot$ Medical education $\cdot$ Volunteering

The COVID-19 pandemic has vastly disrupted medical education and student life, forcing academic and hospital administrators as well as medical students to rapidly develop novel solutions for unprecedented challenges. Removed from the wards for safety yet clamoring to assist, the role of students was particularly nebulous. New processes, policies, and systems were swiftly invented and implemented as the virus spread across the country, stretching the limits of creativity and adaptability for both educators and trainees [1-3].

Across the globe, the role of medical students during the pandemic has been earnestly debated [4-7]. Numerous groups of student volunteers decided not to wait for the debate to settle and instead took action, demonstrating medical students' drive to aid their communities and fellow healthcare workers even in the face of danger and uncertainty [8-10]. Although there were many

Annie Yang

awy13@scarletmail.rutgers.edu

1 Rutgers New Jersey Medical School, 185 S Orange Ave, Newark, NJ 07103, USA

2 Center for Emergency Preparedness and Response, University Hospital, Newark, NJ, USA

3 Office of Education, Department of Pediatrics, Rutgers New Jersey Medical School, Newark, NJ, USA similarities across volunteer groups, each group developed their own unique response to their local situation, balancing the need to protect students against a commitment to their communities. Administrators too faced the challenges of the unknown, rapidly drafting new policies to keep students safe and schools operational [11, 12].

In this perspective, we explore the ways in which students, school administrators, and hospital administrators approached the issue and each other when developing a response to the pandemic, specifically regarding student volunteering. We discuss the viewpoints of these stakeholders during the formation, organization, and operation of the medical student volunteering group at Rutgers New Jersey Medical School (NJMS), highlighting the perspectives of education and hospital leadership. We chronologically illustrate the thought processes and concerns of each of these groups as the first wave of the pandemic progressed throughout the spring of 2020, and we provide recommendations for any similar teams of student volunteers and administrators that may form to combat future threats. 


\section{Before the Wave: What Do We Do With Students?}

\section{Hospital Center for Emergency Preparedness}

During this time, the hospital was primarily focused on centralized communication, educating and training staff about the virus and proper safety precautions, allocation of personal protective equipment (PPE), and surge planning. Each school was making their own decisions regarding student safety and suspending students from clinical involvement. From the hospital's perspective, removing students was not something being considered during the early stages of surge planning. However, as COVID patients began to outnumber other patients, and there were still questions regarding how COVID was being spread, the hospital realized that removing students from clinical rotations would be necessary to decrease transmission rate, reduce PPE burn rate, and increase safety for both students and patients. Everyone in the hospital including physicians, nurses, students, technicians, and environmental services were pieces of the patient care puzzle. Students have some training and can be important contributors to patient care. However, our main goal in the hospital was preserving patient lives, not educating students, and so taking students off the front line made the most sense for this goal. Ultimately, the decision to remove students from the hospital was made by the medical school. While there were some discussions about involving students in non-clinical ways, it was challenging to coordinate student involvement across the multiple Rutgers entities such as the medical, dental, and nursing schools.

\section{Medical School Administration}

As the pandemic slowly started to unfold, the most important priority was maintaining student safety. As COVID rates escalated nationwide, and so much was still unknown about the spread of the virus early on, we were concerned with our ability to adequately protect our students, even with sufficient personal protective equipment (PPE). At the time, the risks of students remaining on clinical rotations outweighed the benefits. During this whirlwind of a time, knowledge regarding COVID-19 was rapidly evolving and changing, and in response, critical decisions related to education and student safety were at the forefront of our decision making. We wear many hats: clinicians, administrators, residency program directors, and medical school educators. Balancing these can be a challenge, especially with the understanding that graduating medical students are an essential component for the next class of residents.

The medical school leadership was triaging and prioritizing the needs by each class of medical students with priorities initially to ensure that our 4th years would fulfill graduation requirements, 1 st year students could transition to an entirely remote organ system curriculum, and create a hybrid model of remote learning with planned clinical make-up at a later time for 3 rd year students. The 2 nd year class had already completed their organ system curriculum and were studying for USMLE Step 1.

\section{Medical Students}

During the early stages, we were primarily concerned about the quality of our education and our safety, and the degree to which we were being exposed to the virus by attending lectures or clinical rotations. There were mixed opinions on the severity of the virus and the justification for suspending educational experiences, especially clinical rotations. Some of us wanted to be immediately released from clinical duties, while others were more skeptical about the need for such a drastic response, and some even felt that this was a once-in-a-lifetime medical educational experience. Such ambiguity was not unique to NJMS [13].

Students already rotating on the hospital floors, regardless of their opinion of the necessity of canceling rotations, were united in their dismay and disappointment at such a development. Layered on this sadness was a pervasive sense of anxiety, especially for second and third year students approaching steps 1 and 2 licensing exams, as this was uncharted territory, and we had no idea how this would affect our exams, graduation requirements, or the residency process. Information from AAMC, LCME, and NBME, and even our school administration seemed to be evolving on a daily basis. For many, volunteering was a distant thought in the face of these pressing personal concerns.

As the pandemic wave began to surge (and in-person education was deferred seemingly indefinitely), priorities changed. For students already living or moving back home, many daily decisions were now filtered through the lens of protecting medically vulnerable family members. For others, new-found time and the desire to use the skills and resources we had led to the brainstorming of ways in which we could help healthcare workers or the community despite being removed from clinical roles. Individual creativity snowballed in the age of social media, and groups of strangers in campuses spread across the country began to share and implement plans [14]. 


\section{As the Wave Crested: How Can Students Get Involved?}

\section{Hospital Center for Emergency Preparedness}

During the height of the surge, it was difficult to find time to properly on-board and train students for tasks that could help the hospital, leading to potential delays in the initiation of student involvement. The areas in which student assistance was most appreciated was with working in the canteen for PPE distribution to healthcare workers, conducting temperature screenings at hospital entrances, and assisting with respiratory protection measures. These tasks were critical because it allowed hospital staff to return to their normal jobs. The hospital felt the "wellness spaces" created by students were critical for addressing the mental health of healthcare workers and were greatly appreciated by the staff. Student efforts to acquire PPE also helped to maintain a 90-day level of PPE as required by federal requirements.

\section{Medical School Administration}

Our initial focus was on the academic and student affairs' components, including creating remote learning experiences, ensuring students were meeting LCME requirements for graduation, and overall student well-being with daily conversations with students regarding academic, career, and personal support. We also had to figure out how to create a safe space for medical students to return and complete their critical clinical education as to not break the chain in the continuum of medical education. Our close relationship with the hospital was critical in this process ensuring availability of appropriate PPE and allowing our students to eventually return to the wards in the summer.

Admittedly, student volunteer efforts were not on the forefront of our initial work. The NJMS Student COVID Team leadership contacted the leadership within the office of education and student affairs a few weeks after suspension of clinical rotations. We were generally supportive of student efforts, but as initiatives started to grow and develop, concern for student safety remained the number one priority, and there was hesitation about endorsing activities that permitted students to be removed from isolation and be in close contact with other individuals. If this occurred, we wanted to ensure that proper protections were in place. For example, there were concerns for potential student exposure while providing childcare support for healthcare workers and for volunteering efforts that occurred at the hospital, such as temperature screenings and meal distributions. For efforts on-site at the hospital, student health created a screening questionnaire in order to clear students to volunteer for on-site hospital activities. We were truly amazed by the number of projects the students developed, the number of overall students involved, the connections with other community organizations, and the impact on the community overall, all initiated, implemented, and led by the students themselves. The students' commitment to our hospital, healthcare providers, and community can serve as a model for future community outreach in times of local, state, and national disasters.

\section{Medical Students}

There was a wide spectrum of opinions among students regarding our role, and while the opinions of individuals evolved, major divisions persisted. Despite knowing the dire situation in some hospitals, some students desired to be involved in any form of patient care regardless of exposure risk. For others, initial enthusiasm waned with increasing fears for personal and family safety. A small but vocal few viewed things in a more transactional way, wanting elective credit or financial compensation in exchange for labor and personal risk. There was significant concern over whether volunteering would be might be coercive in image or actuality. Those staying home to protect their parents and children feared that residencies would pass them over in favor of those with tales of COVID heroism, despite the fact that both actions demonstrated commitment to aiding the fight against the pandemic. In particular, the concrete need for some activities to be on-site, and the hard rule against remuneration or credit for volunteering, were major obstacles for a large fraction of the class, reducing the pool of possible volunteers. A common compromise that arose as schools wrestled with this problem in parallel was to restrict volunteer initiatives to non-clinical environments. This was our approach as well, and as more students came forward with ideas for support that fit this framework, an organizational structure began to develop.

Ultimately, most volunteer initiatives developed by our school's students in response to COVID-19 were not directly related to clinical care, and only some took place on the hospital grounds (Table 1). Many of our initiatives were remote, such as virtual tutoring and student wellness initiatives, or were removed from any direct patient contact, such as the state COVID hotline and PPE procurement taskforce. These projects turned out to be among the most popular opportunities for our students to volunteer with, due to a combination of safety concerns and convenience of remote options, as many students had by then already moved back home with family and away from the medical school. 
Table 1 NJMS student COVID team categories of activities

\begin{tabular}{ll}
\hline Activity category & Description \\
\hline Clinical support & Our clinical support branch was the closest to a clinical environment, volunteering just inside the hospital. \\
& Student volunteers screened staff and visitors at the doors for COVID-19 symptoms, distributed allotted \\
& PPE to healthcare workers, fit-tested workers for face masks, and assisted in telemedicine initiatives to make \\
& follow-up phone calls to COVID-19 patients \\
Our team developed multiple wellness initiatives, including the formation of dedicated relaxation and refu- & eling spaces on the floors for healthcare workers, delivered meals directly to the hospital daily, and provided \\
virtual mental and physical health opportunities such as live yoga sessions and a student wellness hotline & Our PPE procurement team worked to gather PPE donations from the community, formed partnerships with \\
local businesses to 3D print reusable face shields, and assembled and delivered PPE to local hospitals & \\
PPE taskforce & This branch of our volunteer organization focused on helping healthcare workers with household support, \\
including providing in-home childcare and pet care, one-on-one tutoring services, and running errands like \\
shopping for groceries and other necessities \\
Multiple projects were created to aid the community during the pandemic, including a virtual tutoring service \\
for K- 8 schools that spread far beyond our home state to 12 different states and 3 countries, fresh produce \\
distribution which continues to deliver weekly groceries to nearly 2000 senior and immigrant families, and \\
the NJ Poison Information \& Education System Community Hotline where volunteers answered general \\
questions pertaining to COVID-19
\end{tabular}

\section{As the Waters Recede, For Now: What Can We Do Better Going Forward?}

\section{Assess and Address the Community's Needs}

For students, the desire and enthusiasm to help should be directed toward an actual, tangible need demonstrated by your community or local hospital. While ideas and responses at other schools may sound worthwhile, they may not be directly reproducible or appropriate at your own institutions. For example, when our hospital's Office of Community Affairs and chaplaincy service were looking for student volunteers to assist with meal distribution and coordinating calls to the family of patients, respectively, these were organic requests that led to students rapidly organizing a response that could fulfill an immediate need. On the other hand, we received fewer requests for childcare than we originally expected, in contrast to the demand displayed by some other communities nationwide. Requests from the hospital staff are a good place to start; otherwise, you can reach out to key stakeholders to make inquiries and perform an informal needs assessment.

\section{Develop an Organized Student Structure}

Having a well-delineated organizational structure will help with team efficiency and delegation of responsibilities and tasks. During the early stages of constant planning and growth, we found this challenging given the rapid changes we saw in community needs, project ideas, and number of volunteers. Other considerations include having a centralized email and virtual workspace app to ensure successful and rapid communication, as well as establishing a strong social media presence to motivate and recruit additional student volunteers. While the resources we mustered were centralized, the various teams of the NJMS volunteering effort were more federated, each able to operate mostly independently. This hybrid solution promoted more open collaboration and reduced duplication of efforts as independently started groups were readily able to join the larger coalition and share its resources when needed.

\section{Representation to Streamline Communication Between Students and Hospital}

From the hospital side, we would recommend designating an individual within the Incident Command System (ICS) structure to act as a liaison with students. This individual would be self-sufficient and have the capability of managing volunteers and resources with minimal need to refer to those who are more senior. Similarly, there should be a student representative present at relevant high-level meetings (such as our hospital's all-department briefing every morning), so that they can have a better grasp of how the hospital is running and where the current needs are, and, in turn, communicate their findings to fellow students. Since Rutgers has various health professional schools within the university's division of health sciences, a streamlined mode of communication among the various schools and the hospital would have also improved communication and the relaying of consistent messaging to the various student bodies.

\section{Consistent Communication Between Students and Academic Administrators}

There should be regularly scheduled meetings between designated student volunteer, hospital, and school representatives 
to ensure organized and continuous communication. It would be helpful to have the entire leadership team with representatives from each activity meet together with hospital and medical school leadership on a regular basis. Such planned and structured meetings would allow all parties to have a clear understanding of plans, decisions, and the development of projects. Furthermore, all parties should set clear expectations from the very beginning, including roles of each group, and discussion regarding communication with the student body as a whole as well as potential for credit toward academic progression.

\section{Plan for Continuity in the Second Wave and Beyond}

In order for student volunteers to have a role in the planned response to a resurgent or future outbreak, there needs to be continuity in volunteer leadership, as well as an institutional champion. When planning for sustainability, we should acknowledge that the staff generally remains longer than any student, and so institutional support is key. One form that this could take is if advancing students recruit incoming students, similar to other clubs, and link them directly with the relevant hospital administrator in the ICS structure. With the experience gained during COVID-19, the potential roles for student volunteers can be anticipated and largely planned for. Rather than recruiting ad hoc for newly sprouting roles, recruitment should be for a general student labor pool, with the flexibility to be deployed by student leaders to address whatever needs are identified by hospital leadership in an evolving situation. This could help prevent redundancy in response, free up resources for the hospital, and reduce potential liability issues [15]. Schools may even choose to incorporate pandemic preparedness into their curriculum which may increase the size and skillset of a potential volunteer response [16].

It is important to acknowledge that the role of students will change over time. At our school, clinical students (third and fourth years) were welcomed back onto the floors after the initial spring peak wound down. Despite smaller waves later on, the hospital was able to segregate most COVID patients into non-teaching services and floors, keeping the experience of clinical students mostly unchanged. They were also permitted to join the first wave of vaccinations, which in combination with ample PPE supplies, partially assuaged the fears of administrators. In contrast, pre-clinical students remained remote, and many moved away from the hospital and back in with vulnerable unvaccinated family. The hospital itself was able to streamline its pandemic measures for example, tasking entry security guards with temperature screenings - which reduced reliance on the student labor pool. As such, the nature of volunteering changed. Students, especially clinical year students, were less involved in direct in-hospital laboring but maintained a role in telehealth operations such as the State COVID Hotline and follow-up calls for patients under investigation, as well as more community-focused initiatives like neighborhood food delivery.

\section{Conclusion}

Our collective experience in working together - as students, educators, and administrators - in developing a coordinated student volunteer response to the pandemic required significant adaptability by all parties and involved the creation of new roles and responsibilities. Everyone was pulled away from their "normal" jobs to form solutions to an unprecedented challenge.

The lack of data and information contributed to the sense of confusion and uncertainty when making decisions. At the start of the pandemic, new information was being released daily and often asymmetrically, but going forward, students and administrators - now armed with better evidence and precedent about how to ensure safety - will be able to work together to help support the hospital and healthcare workers. To build an impactful and effective student volunteer response, we believe all future efforts should have streamlined and consistent communication among the various stakeholders, in particular the presence of designated student representatives in key stakeholder meetings.

We believe the lessons we learned are applicable to students and trainees of all health professions, including dental, nursing, and physician assistants, among many others. We hope that this piece can help future teams of students, schools, and hospitals work more cohesively to approach future natural disasters like the COVID-19 pandemic.

Acknowledgements The authors would like to express their immense gratitude toward all of the healthcare professionals and administrators that have worked tirelessly throughout the pandemic. They would also like to thank Peter Alsharif, Archana Babu, David Elson, Nashali Ferrara, Anushka Sindkar, and all of the other student leaders and volunteers of the NJMS Student COVID Team that have devoted their time and energy to serving the patients and communities of Newark and University Hospital.

Author Contribution The first draft of the commentary was written by Annie Yang, Scott Fabricant, and Ashley Ooms. All authors read and approved the final manuscript.

\section{Declarations}

Conflict of Interest The authors declare no competing interests.

\section{References}

1. Haines MJ, Yu ACM, Ching G, Kestler M. Integrating a COVID19 volunteer response into a Year-3 md curriculum. Med Educ. 2020. https://doi.org/10.1111/medu.14254. 
2. Hofmann H, Harding C, Youm J, Wiechmann W. Virtual bedside teaching rounds with patients with COVID-19. Med Educ. 2020. https://doi.org/10.1111/medu.14223.

3. Caplan J, Clements R, Chadwick C, Kadirgamar J, Morgan J, Medical RA, Education in, . Developing COVID secure undergraduate hospital placements. Med Sci Educ. 2020;2020:1-7. https://doi.org/10.1007/s40670-020-01080-2.

4. Gallagher TH, Schleyer AM. We signed up for this! - student and trainee responses to the Covid-19 pandemic. N Engl J Med. 2020;382(25):e96. https://doi.org/10.1056/NEJMp2005234.

5. Menon A, Klein EJ, Kollars K, Kleinhenz ALW. Medical students are not essential workers: examining institutional responsibility during the COVID-19 pandemic. Acad Med. 2020;95(8):1149-51. https://doi.org/10.1097/ACM.0000000000003478.

6. Miller DG, Pierson L, Doernberg S. The role of medical students during the COVID-19 pandemic. Ann Intern Med. 2020;173(2):145-6. https://doi.org/10.7326/M20-1281.

7. Stokes DC. Senior medical students in the COVID-19 response: an opportunity to be proactive. Acad Emerg Med. 2020;27(4):343-5. https://doi.org/10.1111/acem.13972.

8. Schuiteman S, Ibrahim NI, Hammoud A, Kruger L, Mangrulkar RS, Daniel M. The role of medical student government in responding to COVID-19. Acad Med. 2020. https://doi.org/10. 1097/ACM.0000000000003542.

9. Soled D, Goel S, Barry D, Erfani P, Joseph N, Kochis M, et al. Medical student mobilization during a crisis: lessons from a COVID-19 medical student response team. Acad Med. 2020. https://doi.org/10.1097/ACM.0000000000003401.
10. Klasen JM, Meienberg A, Nickel C, Bingisser R. SWAB team instead of SWAT team: medical students as a frontline force during the COVID-19 pandemic. Med Educ. 2020. https://doi.org/10. 1111/medu.14224.

11. Samarasekera DD, Goh DLM, Lau TC. Medical school approach to manage the current COVID-19 crisis. Acad Med. 2020;95(8):11267. https://doi.org/10.1097/ACM.0000000000003425.

12. Goldenberg MN, Hersh DC, Wilkins KM, Schwartz ML. Suspending medical student clerkships due to COVID-19. Med Sci Educ. 2020:1-4. https://doi.org/10.1007/s40670-020-00994-1.

13. Compton S, Sarraf-Yazdi S, Rustandy F, Radha Krishna LK. Medical students' preference for returning to the clinical setting during the COVID-19 pandemic. Med Educ. 2020. https://doi.org/ 10.1111/medu.14268.

14. Huddart D, Hirniak J, Sethi R, Hayer G, Dibblin C, Meghna Rao $\mathrm{B}$, et al. \#MedStudentCovid: how social media is supporting students during COVID-19. Med Educ. 2020. https://doi.org/10. 1111/medu.14215.

15. Kratochvil TJ, Khazanchi R, Sass RM, Caverzagie KJ. Aligning student-led initiatives and incident command system resources in a pandemic. Med Educ. 2020. https://doi.org/10.1111/medu. 14265.

16. O’Byrne L, Gavin B, McNicholas F. Medical students and COVID-19: the need for pandemic preparedness. J Med Ethics. 2020. https://doi.org/10.1136/medethics-2020-106353.

Publisher's Note Springer Nature remains neutral with regard to jurisdictional claims in published maps and institutional affiliations. 